\title{
Abordagem Familiar: aplicação de ferramentas a uma família do município de Montes Claros/MG
}

\section{Family Approach: application of tools in a family from Montes Claros/MG Abordaje Familiar: aplicación de herramientas para una familia do Municipio de Montes Claros/MG}

Anne Raissa Souza Dias Brante. Universidade Estadual de Montes Claros (UNIMONTES). Montes Claros, MG, Brasil. anneraissa@bol.com.br (Autora correspondente)

Danuse Silveira Martins. Universidade Estadual de Montes Claros (UNIMONTES). Montes Claros, MG, Brasil. dannyteclas@ hotmail.com Fabrícia Maria Visu Neves. Universidade Estadual de Montes Claros (UNIMONTES). Montes Claros, MG, Brasil.

fabricia.visu@yahoo.com.br Janette Caldeira Fonseca. Universidade Estadual de Montes Claros (UNIMONTES). Montes Claros, MG, Brasil. janettecaldeirafonseca@yahoo.com.br Julimary Larissa Mendes Ottoni. Universidade Estadual de Montes Claros (UNIMONTES). Montes Claros, MG, Brasil. julyottoni@yahoo.com.br Renata Francine Rodrigues de Oliveira. Universidade Estadual de Montes Claros (UNIMONTES). Montes Claros, MG, Brasil. renatafrancine@gmail.com

\section{Resumo}

Introdução: As ferramentas de abordagem familiar assumem caráter essencial na Atenção Primária à Saúde e são referenciadas como úteis e assertivas no trabalho com famílias. Objetivo: Realizar intervenção num domicílio da abrangência da ESF São Geraldo, Montes Claros/MG, a partir das ferramentas de abordagem familiar. Métodos: Foi realizada revisão de literatura na Biblioteca Virtual em Saúde, bem como em em livros acerca da temática em questão. Posteriormente foram realizados oito encontros com a família para aplicação das seguintes ferramentas de abordagem familiar: Genograma, Ciclos de Vida, FIRO, PRACTICE e Conferência Familiar. Resultados: Percepção da dinâmica familiar para esclarecimento das situações de conflito que interferem nas condições de saúde de alguns de seus membros, estabelecimento de acordos com a família no sentido de melhorar a qualidade de vida da família em estudo. Conclusão: A abordagem familiar possibilitou maior proximidade entre equipe de saúde e usuários do serviço, compreendendo as questões emocionais que interferem negativamente no quadro clínico do paciente índice e seus familiares. Foi possível também iniciar um trabalho com foco na mudança dos comportamentos disfuncionais da família.

\section{Abstract}

Introduction: Family approach plays an essential role in primary healthcare and is considered useful and effective in working with families. Objective: To perform an intervention in a home covered by the ESF São Geraldo, Montes Claros/MG, based on the family-tools approach. Methods: We performed a literature review on the subject in the Virtual Health Library and then had eight meetings with the family to implement the following tools: Genogram, Lifecycle, FIRO, PRACTICE, and Family Conference. Results: The approach affected perception of family dynamics to clarify conflict situations that interfere with the health status of some of its members and establishment of agreements with the family to improve quality of life. Conclusion: The Family Approach allowed greater proximity between health staff and service users, including the emotional issues that interfere negatively with the clinical features of the index patient and his/her family. It was also possible to start a job focused on changing dysfunctional family behaviors.

Como citar: Brante ARS, Martins DS, Neves FMV, Fonseca JC, Ottoni JLM, Oliveira RFR Abordagem Familiar: aplicação de ferramentas a uma família do município de Montes Claros/MG. Rev Bras Med Fam Comunidade. 2016;11(38)1-9. http://dx.doi.org/10.5712/rbmfc11(38)953
Palavras-chave: Relações Familiares Estratégia de Saúde da Família Atenção Primária à Saúde Equipe Interdisciplinar de Saúde Comunicação Interdisciplinar

\section{Keywords:}

Family Relations Family Health Strategy Primary Health Care Patient Care Team Interdisciplinary Communication

Fonte de financiamento: declaram não haver. Parecer CEP: 572.244 (UNIMONTES), aprovado em 27/03/2014 Conflito de interesses: declaram não haver. Procedência e revisão por pares: revisado por pares. Recebido em: 19/06/2014. Aprovado em: 18/10/2015. 


\section{Resumen}

Introducción: Las herramientas del enfoque familiar asumen carácter esencial en la Atención Primaria de Salud, y se hace referencia tan útil y asertivo en el trabajo con las familias. Objetivo: Realizar la intervención en una casa cubierta por el ESF São Geraldo, Montes Claros/MG, desde el enfoque de la familia-herramientas. Métodos: Se realizó una revisión de literatura en la Biblioteca Virtual en Salud, así como libros sobre el tema en cuestión. Posteriormente se celebraron ocho reuniones con la familia para poner en práctica las siguientes herramientas de enfoque familiar: Genograma, Life Cycles, FIRO, la práctica y la Conferencia de la Familia. Resultados: Percepción de la dinámica familiar para aclarar las situaciones de conflicto que interfieren con el estado de salud de algunos de sus miembros, el establecimiento de acuerdos con la familia para mejorar la calidad de vida de la familia en estudio. Conclusión: El enfoque familiar permitió una mayor proximidad entre el personal sanitario y los usuarios del servicio, incluidas las cuestiones emocionales que interfieren negativamente con las características clínicas del paciente índice y su familia. También fue posible iniciar un trabajo centrado en el cambio de comportamientos disfuncionales de la familia.
Palabras clave:

Relaciones Familiares

Estrategia de Salud Familiar Atención Primaria de Salud Grupo de Atención al Paciente Comunicación Interdisciplinaria

\section{Introdução}

A abordagem familiar assume caráter essencial no trabalho na atenção primária em saúde. Nesse âmbito a Estratégia de Saúde da Família - ESF foi definida como reorientação do modelo de assistência que atua com equipes multiprofissionais em unidades de atenção primária à saúde. ${ }^{1}$

A família pode ser conceituada como grupo de pessoas que interligadas por laços emocionais ou consanguíneos compartilham uma história em comum. ${ }^{2}$ Trata-se de um conjunto de pessoas, ligadas por laços de parentesco, por dependência doméstica ou normas de convivência, que residem no mesmo domicílio. ${ }^{3}$

AAbordagem Familiar é um dos princípios propostos por Starfield ${ }^{4}$ para a Atenção Primária à Saúde e remete ao conhecimento, pela equipe de saúde, dos membros da família e dos seus problemas de saúde.

Ao compreender os padrões das famílias atendidas dá-se um passo importante para realização de intervenções condizentes com o contexto social em que estão inseridas. Nesse sentido, as ferramentas de abordagem familiar são úteis e assertivas no trabalho com famílias. ${ }^{5,6}$

Dentre as ferramentas de abordagem familiar o Genograma, desenvolvido na América do Norte, apresenta a estrutura e o padrão de repetição das relações familiares. ${ }^{7}$ Trata-se de um método de coleta e processamento de dados sobre a família que possui potencial para ilustrar dados de uma forma rápida, incluindo seu passado hereditário, potenciais problemas de saúde, influências sociais, ocupacionais, aspectos religiosos, dentre outros. ${ }^{6}$

O Ciclo de Vida Familiar trata-se de uma ferramenta que permite identificar fenômenos que envolvem cada estágio de desenvolvimento pelo qual passa a família. A compreensão desses ciclos possibilita à equipe de saúde prever quando e como as doenças podem ocorrer. ${ }^{8}$ Por exemplo, saber que no Estágio Lançando os Filhos e Seguindo em Frente o princípio-chave é a aceitação de várias entradas e saídas no sistema familiar em que é preciso reestabelecer o relacionamento conjugal como díade; mudar o status de relacionamento com os filhos, agora adultos; incluir parentes por afinidade e netos na família e conviver com a perda de capacidades e mortes de avós; permite que as equipes tenham ideia de quais agravos à saúde determinada família está mais suscetível e, a partir desse conhecimento os profissionais poderão planejar ações de saúde mais assertivas. ${ }^{9}$

A ferramenta FIRO (Fundamental Interpersonal Relations Orientation), originalmente desenvolvida por Schultz no estudo de grupos adaptado para estudos e terapia de famílias por Doherty e Colengelo ${ }^{10}$ baseia-se em Orientações Fundamentais nas Relações Interpessoais em que se busca compreender o 
funcionamento da família a partir de suas relações de poder, comunicação e afeto. Estudam-se as dimensões de inclusão, controle e intimidade. A inclusão refere-se à interação dentro da família para sua vinculação e organização. O controle refere-se às interações do exercício de poder dentro da família, o qual pode ser dominante, quando um exerce influência sobre todos os demais; reativo, quando se estabelecem reações contrárias a uma influência que quer tornar-se dominante e colaborativo, quando há divisão de influências entre os familiares. Já a intimidade refere-se às interações familiares correlatas às trocas interpessoais, ao modo de compartilhar sentimentos, ao desenvolvimento de atitudes de aproximação ou de distanciamento entre os familiares e às vulnerabilidades e fortalezas. ${ }^{10,11}$

A ferramenta PRACTICE foi um instrumento projetado por médicos de família útil na avaliação do funcionamento da família, no que se refere a um caso específico. ${ }^{10}$ Disponibiliza informações sobre a organização e posicionamento da família diante dos problemas, foca no problema existente e permite uma aproximação esquematizada para trabalhar com a família, facilitando a coleta de informações e a elaboração de intervenções. ${ }^{11}$ Cada letra significa um termo, a saber: Presenting problem (problema apresentado) refere-se ao modo como a família vê o problema e tenta superá-lo; Roles and structure (papéis e estrutura) que diz respeito ao modo como cada membro desempenha e evolui o seu papel; Affect (afeto) refere-se à maneira como o afeto é demonstrado pelos membros da família e como isso interfere no contexto familiar; Comunication (comunicação) esclarece como se dá a comunicação verbal e não verbal dentro da família; Time of life cycle (fase do ciclo de vida) diz respeito à relação entre o problema e as tarefas condizentes com o ciclo de vida; Illness in family (doença na família) demonstra a história de morbidade familiar, valorizando as atitudes de cuidado; Coping with stress (enfrentamento do estresse) refere-se ao potencial que a família tem para lidar com o problema; Ecology (meio ambiente, rede de apoio) diz respeito aos recursos ambientais, sociais e familiares que podem ser explorados para superação do problema. ${ }^{11}$

A Conferência familiar é uma ferramenta utilizada em situações de conflitos em que o profissional aborda questões de saúde, interação e comunicação entre membros da família. ${ }^{12}$ É uma reunião, previamente planejada, entre os membros da família, em que se trabalha a partilha da informação e de sentimentos com objetivo de mudar alguns padrões interacionais na família. ${ }^{13}$

As ferramentas de abordagem familiar descritas acima são relevantes no caso em questão, uma vez que permitem visualizar a dinâmica da família, os relacionamentos intrafamiliares e padrões disfuncionais, favorecendo intervenções mais eficazes e condizentes com a realidade. Nesse sentido, o referido trabalho teve como objetivo realizar intervenção num domicílio da abrangência da ESF São Geraldo, Montes Claros/MG, a partir das ferramentas de abordagem familiar.

\section{Descrição da experiência}

Trata-se de um relato de experiência de abordagem metodológica qualitativa, desenvolvido durante o primeiro semestre de 2014 pela equipe multiprofissional composta de uma Enfermeira, uma Cirurgiã-Dentista e uma Psicóloga, integrantes de um Programa de Residência Multiprofissional em Saúde da Família de uma universidade da cidade de Montes Claros/MG.

O território da área da abrangência da ESF São Geraldo está localizado na zona sul do município de Montes Claros/MG e atende cerca de 3.353 pessoas distribuídas em 854 famílias. 
A família foi selecionada considerando que o paciente índice, apresentou quadro de diabetes descompensada, hipertensão arterial descontrolada e resistência ao uso de medicação prescrita. Percebeu-se ainda humor triste, desesperança no futuro e conflitos familiares frequentes. O mesmo procurava constantemente a ESF com demandas por atendimento. Nesse sentido, acredita-se que o quadro clínico do paciente e suas queixas podem ter influencia do contexto em que vive e das disfuncionalidades da família.

Antes iniciar o estudo a família foi consultada quanto ao seu interesse em participar e foram esclarecidos os termos desta participação, conforme dispõe a Resolução 466/12. ${ }^{14}$ O referido trabalho foi submetido ao Comitê de Ética em Pesquisa da Universidade Estadual de Montes Claros - UNIMONTES e aprovado em 27 de março de 2014, conforme parecer no 572.244 de 27/03/2014.

Inicialmente foi feita uma revisão da literatura nas bases de dados da Biblioteca Virtual em Saúde BVS e Ministério da Saúde, bem como em bibliografia da temática em questão. Em seguida foi feito o primeiro contato com a família. Foram realizados seis encontros com a família para aplicação das seguintes ferramentas de abordagem familiar: Genograma, FIRO, PRACTICE e dois encontros para realização de Pré-Conferência e Conferência Familiar, respectivamente. Foi feito também um atendimento individual ao paciente após a Conferência Familiar para orientações e responsabilização.

A Figura 1, descrita a seguir, apresenta o Genograma da família, que retrata aspectos relevantes da dinâmica familiar, padrões de relacionamento, conflitos, agravos à saúde, dentre outros.

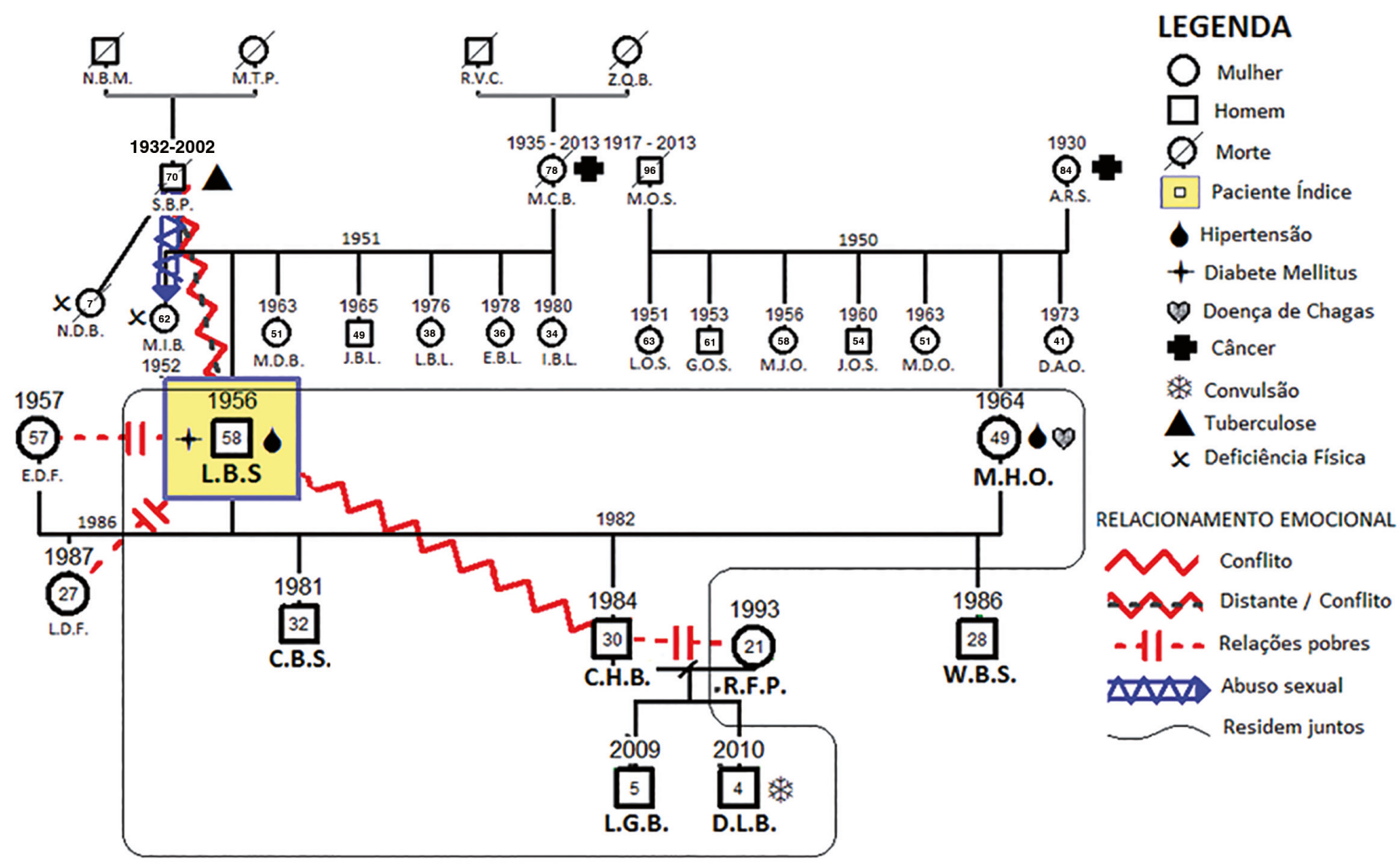

Junho/ 2014

Figura 1. Genograma: aspectos gerais. Fonte: Do autor. 
O paciente índice é o senhor (Sr.) L.B.S., 58 anos, mototaxista, evangélico, hipertenso, diabético, casado com a senhora (Sra.) M.H.O., 49 anos, evangélica, cuidadora de idoso, hipertensa e chagásica. O mesmo sofreu dois acidentes enquanto trabalhava e em decorrência de lesões realizou cirurgia ortopédica no antebraço esquerdo. Após a cirurgia sente que sua capacidade de trabalho ficou limitada, por isso deseja aposentar-se.

O casal possui três filhos, sendo o mais velho, C.B.S., 32 anos, solteiro, designer de interiores, sem religião definida. O segundo filho é C.H.B., 30 anos, evangélico, frentista. O mesmo foi casado com R.F.P. e com ela teve dois filhos: L.G.B., 5 anos e D.L.B., 4 anos, epiléptico. O filho caçula do casal é W.B.S., 28 anos, solteiro, evangélico, policial militar que reside em Belo Horizonte/MG. O casal, C.B.S. e os netos moram na mesma residência, sendo que C.H.B. reside no segundo pavimento sozinho. A Sra. A.R.S., 84 anos, sogra de L.B.S. encontra-se na residência há dois meses para tratamento de saúde.

Seu pai, S.B.P., faleceu há 12 anos de tuberculose pulmonar e sua mãe M.C.B. faleceu há 10 meses de câncer no pulmão. Possui seis irmãos, sendo eles: M.I.B., M.D.B., J.B.L., L.B.L., E.B.L. e I.B.L.

Quanto à saúde, o Sr. L.B.S. descreveu episódio de "amnésia" em que necessitou de hospitalização, o que possivelmente está associado às complicações do Diabetes. Referiu também algumas dificuldades, como dores no corpo que geram dificuldades para movimentar os membros superiores.

Entre seus familiares observa-se o caso de M.I.B. que possui dificuldades para deambular devido a problemas no quadril e joelhos. M.I.B. sofreu abuso sexual por parte do pai, S.B.P. durante muito tempo. Desse incesto nasceu N.D.B. que era portadora de deficiência física e não deambulava. Posteriormente foi levada pra adoção e faleceu aos sete anos por complicações sistêmicas.

No ano de 1987, o Sr. L.B.S. teve um relacionamento extraconjugal com a Sra. E.D.F. de 57 anos, do qual nasceu L.D.F. atualmente com 27 anos. Isso repercutiu negativamente na família, contudo o casal afirma ter superado os conflitos decorrentes da infidelidade e atualmente o Sr. L.B.S. não possui contato com a Sra. E.D.F e nem com sua filha.

Já na família da Sra. M.H.O., seus pais, M.O.S. e A.R.S., tiveram sete filhos. O Sr. M.O.S. faleceu aos 96 anos, em 2013 de morte natural. Sua mãe A.R.S., tem 84 anos, é diabética, portadora de glaucoma e faz tratamento de câncer de mama.

Quanto aos filhos do paciente índice não se observa nenhuma comorbidade relevante. Nos relatos, a Sra. M.H.O. informou que seu neto L.G.B. possui sinusite, dislipidemia e altos valores de glicemia em exames laboratoriais. O outro neto, D.L.B., faz acompanhamento com neurologista devido a quadro de epilepsia.

Quanto ao Ciclo de Vida Familiar nota-se que o paciente índice e sua esposa encontram-se na fase Lançando os Filhos e Seguindo em Frente, que começa com o lançamento dos filhos e se estende até a aposentadoria. ${ }^{15}$

Ao utilizar a ferramenta FIRO percebeu-se que L.B.S. sente-se incluído. Já o filho, C.H.B. não compartilha dos valores familiares, nem se submete às regras. A família em geral tem pouca conectividade, sendo que os membros não se integram na resolução dos conflitos.

No que se refere ao controle, o Sr. L.B.S. tem pouco controle sobre os demais membros da família. Percebe-se que o mesmo é muito influenciado pela Sra. M.H.O. que tenta estabelecer um domínio do núcleo familiar. Os filhos C.B.S. e W.B.S. estabelecem um controle colaborativo dentro da família, ao passo que C.H.B. demonstra um controle reativo, sendo contrário ao que é imposto pela família. 
Os familiares aparentam ter pouca intimidade entre si, sendo o ambiente familiar de pouca troca interpessoal, já o casal tenta estabelecer uma proximidade entre si.

Ao analisar a ferramenta PRACTICE percebe-se que quanto ao Problema Apresentado, o Sr. L.B.S. procura constantemente a unidade de saúde demandando atendimento. Apresenta altos níveis pressóricos e glicêmicos, resistência em tomar medicação prescrita e quadro de tristeza, desânimo. Notam-se ainda conflitos familiares acentuados que podem agravar o seu quadro clínico. O paciente índice e sua esposa queixam da sobrecarga em cuidar dos netos. Ambos não aprovam o comportamento de C.H.B., visto como pessoa rebelde, que não assume função paterna, deixando para o casal a total responsabilidade da criação dos netos. Quanto aos Papeis e Estrutura, a Sra. M.H.O. assume as funções de mãe, esposa, provedora do lar e avó. Assume ainda as tarefas domésticas. Já o Sr. L.B.S. sente-se inferiorizado em não conseguir ser o provedor financeiro do lar, contudo auxilia no cuidado dos netos e ajuda em algumas tarefas domésticas. $O$ filho C.B.S. está conquistando sua independência financeira e colabora nas despesas domésticas, já o filho C.H.B. não auxilia na manutenção do lar e nem no cuidado com seus filhos. Em relação ao Afeto, percebe-se que o paciente índice possui relacionamento estreito com a esposa e netos, aos quais demonstra muito carinho. Vive em harmonia com dois filhos, contudo tem relação conflituosa, distante e pobre com o filho C.H.B. Acerca da Comunicação, nota-se que é deficiente. O paciente índice não se sente a vontade para expor seu ponto de vista, sendo passivo em relação às questões da família, já sua esposa consegue estabelecer mais diálogo com os membros da família. Sobre o Tempo no Ciclo de Vida, a família está na fase Lançando os Filhos e Seguindo em Frente, mas vive simultaneamente período anterior que seria Família com Filhos Pequenos. Acerca da Doença na Família, percebe-se não há repetições significativas de agravos à saúde do passado, contudo, o quadro de Diabetes pode ocorrer também com o neto do Sr. L.B.S., que tem apresentado níveis glicêmicos elevados. Em relação a Enfrentar o estresse, os membros da família têm dificuldades de lidar com o estresse de forma assertiva, tendendo ao isolamento e falta de esperanças nas mudanças. Alguns membros buscam na religião um apoio emocional. Sobre Ecologia, a família presta assistência aos parentes que moram fora da cidade, que quando necessitam vir a Montes Claros/MG hospedam-se na casa do paciente índice. A frequência com que isso ocorre irrita todos os membros da família, contudo a Sra. M.H.O. sente dificuldade em impor um limite nessas situações. O paciente índice possui poucos contatos com vizinhos e amigos e não possui formas alternativas de suporte externo. O casal geralmente não tem momento de lazer, sendo a Igreja um local de vínculo social saudável, principalmente para a Sra. M.H.O., que colabora em um curso de costura que a instituição oferece à comunidade. As condições da moradia são satisfatórias, a casa é ampla e a limpeza do ambiente é adequada. Os moradores buscam auxílio na ESF quando necessário.

Com o objetivo de mudar padrões disfuncionais familiares, bem como melhorar as condições de saúde do paciente índice foi realizada uma Conferência Familiar com a presença do casal e da sogra do mesmo. ${ }^{13}$ Inicialmente a equipe de saúde acolheu aos participantes e esclareceu os objetivos do encontro. A Sra. M.H.O. expôs sua dificuldade em reunir os familiares, uma vez que os filhos recusaram-se em participar do encontro. Em seguida foram expostos os problemas observados durante aplicação das demais ferramentas, quais sejam: descontrole dos níveis pressóricos e glicêmicos do paciente índice; dificuldade de comunicação entre os membros da família; sobrecarga da família em relação ao cuidado de pessoas da família extensa; dificuldade no desempenho dos papeis familiares e sobrecarga do casal no cuidado dos netos. 
Após exposição dos problemas a família foi ouvida. Acerca dos altos níveis de glicemia e pressão arterial o paciente índice não aparentou comprometimento no controle de sua saúde, atribuindo a Sra. M.H.O. a responsabilidade pelo preparo dos alimentos. Acerca do problema de comunicação entre os membros percebeu-se que o Sr. L.B.S. encontra-se com humor irritado, aborrecendo-se com os filhos e netos por motivos que poderiam ser contornados com diálogo. Em relação à disponibilidade da família, sobretudo da Sra. M.H.O., em acolher parentes e amigos na residência por vários dias, o Sr. L.B.S. expôs que não concorda com essa atitude. A Sra. M.H.O. relatou que se sente sobrecarregada e sabe que a situação tem prejudicado a família. Acerca da dificuldade no desempenho dos papeis familiares, o Sr. L.B.S. relatou o quanto a chegada dos netos para o convívio do casal prejudicou a privacidade deles e afetou planos futuros. A Sra. M.H.O. também concordou com ele, mas disse que não via outra saída, já que os pais das crianças não se responsabilizam pelos filhos. Soube-se também nesse momento que os netos dormiam no mesmo quarto dos avós, apesar da casa possuir outros locais disponíveis para dormitório. A Sra. A.R.S. demonstrou sua indignação em relação às atitudes do bisneto C.H.B. Grande parte das queixas estava direcionada às atitudes de C.H.B.

Após ouvir os familiares a equipe de saúde falou da importância do desempenho adequado dos papeis familiares, da necessidade de uma postura mais flexível que possibilite o diálogo entre os membros da família. Foi dito também da colaboração de toda a família no tratamento do paciente índice.

Ao final da Conferência Familiar foram estabelecidos os seguintes acordos com a família: a Sra. M.H.O. comprometeu-se em preparar a alimentação conforme a dieta recomendada para L.B.S. e irá ajudá-lo também quanto ao uso diário da medicação prescrita; o casal irá solicitar ao filho C.H.B. uma contribuição regular para auxiliar na criação dos dois filhos e tentaria envolvê-lo no cuidado com as crianças; será providenciado um novo local para que as crianças possam dormir, dando mais privacidade ao casal; a Sra. M.H.O. comprometeu-se em rever sua postura de aceitação diante das demandas de hospedagem dos parentes; o Sr. L.B.S. comprometeu-se em comparecer na unidade básica no dia seguinte para uma consulta, onde seriam feitos esclarecimentos acerca de seu estado de saúde e orientações sobre hábitos de vida saudáveis, conforme plano de cuidados da Enfermagem.

No dia seguinte o paciente índice procurou a unidade básica, onde passou por avaliação com a médica e a enfermeira. Na ocasião tentou-se sensibilizá-lo para que seja mais responsável por sua saúde e foram feitas orientações sobre alimentação, uso regular de medicação e hábitos de vida saudáveis.

\section{Discussão}

Acerca do caso apresentado percebe-se que a problemática familiar é complexa e necessita de uma compreensão que leva em conta sua inserção no contexto sócio econômico e no momento do ciclo vivido. Nessa perspectiva, Nascimento et al. ${ }^{16}$ e Vasconcellos ${ }^{17}$ afirmam que investigar a situação evolutiva de uma família pode esclarecer situações de conflitos que interferem nas condições de saúde de algum de seus membros, conforme pode-se perceber no caso descrito.

No estudo em questão a investigação iniciou-se por meio do Genograma, uma vez que o processo de envolver cada membro da família na representação do seu próprio Genograma pode resultar em desdobramentos que favorecem a saúde e o bem-estar dos mesmos e, ainda, o empoderamento da família. ${ }^{16}$ Nessa perspectiva, ao final do trabalho houve relatos de efeitos terapêuticos de se falar da história e dinâmica familiar. 
Percebe-se que o casal encontra-se no período em que os filhos teriam que deixar a casa paterna para serem independentes. Nesse momento é preciso que os membros aceitem as saídas e entradas de pessoas no sistema familiar, lidando com incapacidades e mortes, bem como inclusão de parentes por afinidade e netos. Ao passo que o casal precisa renegociar o sistema conjugal como díade. É necessário ainda que os relacionamentos ganhem novo status entre pais e filhos. ${ }^{9}$

Nessa direção, a família em estudo apresenta dificuldades em lidar com as tarefas dessa nova fase, tanto no que se refere à mudança da função do casamento, quanto no estabelecimento de nova relação com os filhos. O paciente índice apresenta resistências em aceitar a inclusão de novos membros na família como as namoradas dos filhos, desqualificando as possíveis noras como inadequadas para uma relação estável, atitude que inflama conflitos. Por outro lado, o filho C.H.B. é tido como único responsável pelos problemas familiares e mesmo sendo divorciado e morando no andar superior da casa dos pais, não tem uma vida autônoma, sendo a Sra. M.H.O. ainda responsável por cuidar das questões domésticas dele.

Esse cenário exemplifica uma resistência do casal em lançar os filhos, que pode significar dificuldades do casal em lidar com questões conjugais proeminentes nessa fase da relação. É como se a permanência dos filhos em casa e sua dependência dos pais ocupassem tempo e energia emocional, fazendo com que o casal adie reflexões sobre o status do casamento e continue a superfuncionar em função dos filhos, agora adultos e dos netos. Esse estresse familiar é previsto pela literatura nos períodos de transição entre um estágio e outro, sendo os sintomas tendentes a surgir quando há uma interrupção ou deslocamento no ciclo de vida familiar em desdobramentos. ${ }^{9}$

A literatura aponta que nas famílias de classe média o ciclo de vida é mais longo e bem delineado, diferente das de baixa renda, em que as etapas são mais curtas e não costumam serem bem traçadas e nem terem um rito de passagem. Tal como na família apresentada neste estudo, os membros vivem mais de um ciclo simultaneamente, assumindo papéis e funções para as quais não estão preparados, o que tende a comprometer o amadurecimento para o estágio posterior. Questões como desemprego, problemas financeiros, sentimentos de impotência diante dos fatos, dentre outros, sobrepoem-se causando mais estresse ao ambiente familiar. ${ }^{9}$

Ressalta-se ainda que a utilização da Conferência Familiar mostrou-se relevante para o caso em questão, pois oportunizou aos membros da família colocarem-se diante dos problemas e compartilharem responsabilidades. Nesse sentido, autores afirmam que essa tecnologia tem sido eficaz no trabalho com famílias em situações de agravos à saúde. ${ }^{12}$

\section{Considerações finais}

A utilização das ferramentas de acesso à família permitiu maior proximidade entre equipe de saúde e usuários do serviço, possibilitou o estabelecimento e fortalecimento do vínculo com a família, bem como a compreensão das questões emocionais que interferem negativamente o quadro clínico do paciente índice e repercutem também sobre a família.

A interação entre equipe de saúde e usuários possibilitou ainda intervenções mais condizentes com a realidade da família atendida, sendo que nos últimos encontros já se perceberam efeitos terapêuticos 
dessa aproximação. Todavia, muito há que se fazer pelo caso, pois os membros familiares apresentam fortes resistências em modificar padrões de comportamentos disfuncionais já consolidados no ambiente familiar. Nesse sentido, a equipe de saúde coloca-se ainda em trabalho.

\section{Referências}

1. Romagnoli RC. Breve Estudo Institucionalista Acerca do Programa de Saúde da Família. Saúde soc.[Internet]. 2009 Set [cited 2014 Jan 20]; 18(3): 525-536. Available from: http://www.scielo.br/scielo.php?script=sci_arttext\&pid=S010412902009000300016\&lng=pt. DOI: http://dx.doi.org/10.1590/S0104-12902009000300016

2. Minuchin S, Lee W, Simon GM. Dominando a terapia familiar. 2a ed. Porto Alegre: Artmed; 2008.

3. Ministério da Saúde (BR). Guia prático do Programa de Saúde da Família. Brasília: Ministério da Saúde; 2001.

4. Starfield B. Atenção primária: equilíbrio entre necessidades de saúde, serviços e tecnologia. Brasília: Organização das Nações Unidas para a Educação, a Ciência e a Cultura/Ministério da Saúde; 2002.

5. Wagner ABP et al. Trabalhando com famílias em saúde da família. Revista Médica do Paraná. 1999. 57, (1/2): 40-6.

6. Da Silva JV, Santos SMR. Trabalhando com Famílias Utilizando Ferramentas. Revista APS. 2003. 6(2): 77-86.

7. Ditterich RG, Gabardo MCL, Moysés SJ. As ferramentas de trabalho com famílias utilizadas pelas equipes de saúde da família de Curitiba, PR. Saude soc. [Internet]. 2009 Sep [cited 2014 Feb 02]; 18(3): 515-524. Available from: http://www. scielo.br/scielo.php?script=sci_arttext\&pid=S0104-12902009000300015\&lng=en. DOI: http://dx.doi.org/10.1590/S010412902009000300015

8. Ditterich, RG. O Trabalho com Famílias Realizado pelo Cirurgião-Dentista do Programa Saúde da Família (PSF) De Curitiba-PR. [monografia].Curitiba: Pontíficia Universidade Católica do Paraná; 2005.

9. Carter B, Mcgoldrick M. As mudanças no ciclo de vida familiar: uma estrutura para a terapia familiar. 2a ed. Porto Alegre: Artes Médicas; 1995.

10. Wilson L, Talbot Y, Librach L. Trabalhando com famílias: livro de trabalho para residentes. Curitiba: SMS; 1996.

11. Moysés SJ, Silveira Filho AD. Os dizeres da boca em Curitiba: Boca Maldita, Boqueirão, bocas saudáveis. Rio de Janeiro: CEBES; 2002.

12. Lima, JCM, Moraes GLA de; Augusto Filho, RF. O uso da conferência familiar na resolução de conflitos de uma família com idosa dependente. Rev Bras Med Fam e Com. [Internet]. 2008. [cited 2014 Feb 08]. Available from: http://rbmfc.org. $\mathrm{br} / \mathrm{rbmfc} /$ article/view/195/146. DOI: 10.5712/rbmfc4(14)195

13. Galriça Neto I. A conferência familiar como instrumento de apoio à família em cuidados paliativos Revista Portuguesa de Medicina Geral e Familiar [Internet]. 2003 Janeiro 1; [Cited 2014 Feb 19]; 19(1). Available from: http://www.rpmgf.pt/ojs/ index.php?journal=rpmgf\&page=article\&op=view\&path\%5B\%5D=9906.

14. Brasil. Resolução no 466, de 12 de dezembro de 2012. Dispõe sobre diretrizes e normas regulamentadoras de pesquisas envolvendo seres humanos. Diário Oficial da União. 2013 Jun 13; Seção 1:59. [Cited 2014 Feb 21]. Available from: http:// conselho.saude.gov.br/resolucoes/2012/Reso466.pdf.

15. Mccullugh P, Rutenberg S. Lançando os Filhos e Seguindo em Frente. In: Carter B; Mcgoldrick M. As mudanças no ciclo de vida familiar: uma estrutura para a terapia familiar. 2a ed. Porto Alegre: Artes Médicas; 1995.

16. Nascimento LC, Rocha SMM, Hayes VE. Contribuições do genograma e do ecomapa para o estudo de famílias em enfermagem pediátrica. Texto contexto-enferm. [Internet]. 2005 June [cited 2014 Mar 03]; 14(2): 280-286. Available from: http://www.scielo.br/scielo.php?script=sci_arttext\&pid=S0104-07072005000200017\&lng=en. DOI: http://dx.doi. org/10.1590/S0104-07072005000200017

17. Vasconcellos EM. Educação Popular e a Atenção à Saúde da Família. São Paulo: Hucitec; 1999. 